\title{
PENGARUH FREKUENSI PEMBERIAN PAKAN BERBEDA TERHADAP PERTUMBUHAN DAN SINTASAN HIDUP LARVA TERIPANG PASIR Holothuria scabra
}

\author{
Sari Budi Moria S.", Darmansyah", Rosliwati Arfah") dan Ketut Sugama"
}

\begin{abstract}
ABSTRAK
Penelitian bertujuan untuk mengetahui frekuensi pemberian pakan yang tepat dalam pemeliharaan larva teripang pasir, yaitu: A : 1 kali/hari, B: 2 kali/hari, C: 3 kali/hari dan D: 4 kali/hari dengan padat tebar awal larva 200 individu/liter. Masing-masing perlakuan diulang sebanyak tiga kali. Penelitian dilakukan di laboratorium dengan menggunakan bak volume 100 liter sebanyak 12 buah dan berlangsung selama 21 hari. Suhu air selama penelitian berkisar antara $28-32{ }^{\circ} \mathrm{C}$.
\end{abstract}

Hasil akhir penelitian menunjukkan bahwa persentase pertumbuhan larva stadia "pentactula" dengan frekuensi pemberian 1,2,3 dan $4 \mathrm{kali} /$ hari masing-masing adalah: 15,0; 17,4; 51,0 dan $33,8 \%$. Perlakuan $\mathrm{C}$ menunjukkan hasil yang terbaik $(\mathrm{P}<0,05)$, sementara $\mathrm{A}, \mathrm{B}$ dan $\mathrm{D}$ memberikan hasil yang sama. Untuk sintasan tidak ada perbedaan $(\mathrm{P}>0,05)$ antara masing-masing perlakuan.

\begin{abstract}
The Effect of Feeding Frequencies on the Growth and Survival Rates of Larvae of Sea Cucumber Holothuria scabra. By: Sari Budi Moria S., Darmansyah, Rosliwati Arfah and Ketut Sugama.
\end{abstract}

\begin{abstract}
The purpose of the research was to find out efficient feeding frequencies for sea cucumber larvae rearing. Four different feeding frequencies were treated namely A: once/day, B: twice/day, C: 3 times/day, and D: 4 times/day with initial density of 200 seeds/litre. Three replicates were applied for each treatment. The experiment was conducted under laboratory condition using twelve 100 litres polycarbonate tanks. The range of water temperature was $28-30^{\circ} \mathrm{C}$.
\end{abstract}

The results showed that the growth rate of the larvae with feeding frequencies $1,2,3$ and 4 time/day were $15.0 \% ; 17.4 \% ; 51.0 \%$ and $33.8 \%$ respectively. The treatment $\mathrm{C}$ ( 3 times feeding a day) had the best growth rate $(\mathrm{P}<0.05)$, while $\mathrm{A}, \mathrm{B}$ and $\mathrm{D}$ gave the similar results. The survival rate of larvae for all treatments were not significantly different $(P>0.05)$.

KEYWORDS: Sea cucumber, feeding frequencies, larvae.

\section{PENDAHULUAN}

Teripang pasir Holothuria scabra merupakan satu di antara jenis teripang yang memiliki nilai ekonomis penting baik untuk pasar lokal maupun ekspor (Murdjani dan Notowinarto, 1991; Sudradjat dan Daud, 1992). Volume ekspor teripang pada tahun 1994 sebesar $3.429 .573 \mathrm{~kg}$ dengan nilai 12.898.018 US\$ (Anonymous, 1995b).

Terdorong oleh prospek pasar yang cerah bagi komoditas teripang, maka banyak nelayan melakukan penangkapan di alam secara berlebihan, sehingga akan mengancam kelestarian populasi
(Sudradjat dan Daud, 1992). Berkaitan dengan hal tersebut maka dilakukan usaha pengembangan budidaya teripang.

Budidaya teripang sudah lama dilakukan oleh masyarakat nelayan di Riau, Sulawesi Selatan, Sulawesi Tenggara dan Maluku, namun sampai saat ini benih yang digunakan masih berasal dari alam (Notowinarto dan Suciantoro, 1992). Upaya mengantisipasi masalah tersebut adalah melalui pembenihan di panti pembenih (hatchery). Berdasarkan hal tersebut, sejak awal tahun 1992 Loka Penelitian Perikanan Pantai Gondol-Bali, telah merintis usaha perbenihan teripang pasir.

- Peneliti pada Loka Penelitian Perikanan Pantai Gondol, Bali. 
Pada pemeliharaan larva teripang untuk mencapai pertumbuhan dan sintasan tinggi tergantung beberapa faktor yang harus diperhatikan. Satu di antara faktor yang berpengaruh terhadap sintasan larva menurut Effendie (1979) adalah kuantitas dan kualitas pakan serta frekuensi pemberian pakan. Selanjutnya Jangkaru (1974), juga mengemukakan bahwa frekuensi pemberian pakan merupakan salah satu faktor yang mempengaruhi pertumbuhan ikan dan waktu pemberian pakan berhubungan erat dengan frekuensi pemberian pakan. Berdasarkan hasil penelitian selama pemeliharaan larva teripang pasir dari beberapa jenis pakan alami yang diberikan, ternyata Chaetoceros spp. menghasilkan pertumbuhan dan sintasan yang lebih baik dibandingkan dengan plankton Nannochloropsis oculata dan Tetraselmis chuii (Makatutu et al., 1993).

Dalam pemberian pakan alami satu kali per hari sering didapatkan plankton mati sebelum dimakan oleh larva teripang dan akhirnya meng. endap di dasar bak pemeliharaan larva. Akibat adanya sisa plankton tersebut menyebabkan terjadinya pembusukan sehingga kualitas air media pemeliharaan menurun. Sisa plankton yang mati juga sering ditemui menempel pada tubuh larva yang mengganggu gerak larva dan akhirnya menyebabkan kematian larva. Melihat kondisi tersebut dan dalam rangka mengkaji teknologi pembenihan teripang, maka dilakukan penelitian mengenai frekuensi pemberian pakan alami untuk mengetahui frekuensi yang tepat sehingga diperoleh pertumbuhan dan sintasan yang tinggi.

\section{BAHAN DAN METODE}

Penelitian dilakukan di Loka Penelitian Perikanan Pantai Gondol, Bali selama 21 hari sampai larva mencapai stadium pentactula awal. Dalam penelitian ini digunakan larva teripang pasir stadium auricularia dengan kepadatan 200 individuliter yang diperoleh dari hasil pemijahan induk secara alami. Wadah percobaan menggunakan bak polikarbonat volume 100 liter yang dilengkapi aerasi. Setiap wadah diisi air laut yang telah disaring dengan menggunakan kantong filter sebanyak 75 liter dan dipasang pemanas dengan suhu dipertahankan antara $28^{\circ} \mathrm{C}-30^{\circ} \mathrm{C}$.

Pakan yang diberikan adalah fitoplankton dari jenis Chaetoceros spp. dengan kepadatan 20.000 sel/ml/hari dan pergantian air sebanyak $5-15 \%$ dari volume total setiap dua hari sekali. Perlakuan frekuensi pemberian pakan alami yang diberikan adalah $A: 1$ kali/hari pada pukul 08.00 , B: 2 kali/hari pada pukul 08.00 dan pukul 12.00 , C: 3 kali/hari pada pukul $08.00,12.00$ dan 16.00 dan D: 4 kali/hari pada pukul $08.00,12.00,16.00$ dan 20.00 WITA. Rancangan yang digunakan dalam penelitian ini adalah rancangan acak lengkap dengan empat perlakuan dan setiap perlakuan diulang tiga kali. Untuk mendapatkan data pertumbuhan (kecepatan perubahan stadium) dan sintasan larva dilakukan pengamatan dan penghitungan sampel setiap 3 hari. Pada akhir penelitian dilakukan penghitungan larva untuk menentukan sintasan. Data sintasan yang diperoleh lebih dahulu ditransformasikan ke "arcsin" kemudian dianalisis keragamannya pada selang kepercayaan $95 \%$. Sebagai data penunjang dilakukan pengamatan peubah kualitas air meliputi suhu, salinitas, pH, oksigen, nitrit dan amonia.

\section{HASIL DAN PEMBAHASAN}

Hasil penelitian menunjukkan bahwa frekuensi pemberian pakan yang tinggi memperlihatkan kecenderungan pertumbuhan yang lebih baik. Pada akhir penelitian, persentase tertinggi dari larva yang mencapai stadium pentactula diperoleh pada perlakuan $C(51,0 \%)$, diikuti dengan perlakuan $\mathrm{D}$, $\mathrm{B}$ dan $\mathrm{A}$ masing-masing 33,$8 ; 17,4$ dan $15,0 \%$ (Table 1). Berdasarkan analisis ragam, frekuensi pemberian pakan berpengaruh nyata terhadap pertumbuhan larva teripang pasir $(P>0,05)$. Kecepatan perubahan stadia larva pada perlakuan $C$ berbeda nyata dengan perlakuan $A$ dan $B$, namun tidak berbeda nyata terhadap perlakuan D (Table 2). Keberhasilan pemeliharaan larva teripang pasir sangat ditentukan oleh penyediaan jenis pakan yang berkualitas tinggi, pengaturan jumlah dan jadwal pemberian pakan yang tepat serta pemantauan kualitas air agar memberikan kondisi yang optimal bagi kehidupan larva teripang. Pemberian pakan merupakan kegiatan yang perlu diperhitungkan dalam pengelolaan pakan karena akan mempengaruhi kebutuhan tenaga dan meningkatnya biaya operasional budidaya. Lamanya perkembangan larva pada frekuensi pemberian pakan yang berbeda berdasarkan persentase jumlah larva yang mengalami metamorfosis tidak menunjukkan adanya perbedaan, namun sampai 
akhir penelitian (hari ke 21) masih ditemukan stadium auricularia (Table 1).

Notowinarto dan Putro (1991), menyatakan bahwa selama pemeliharaan larva teripang dapat diberi fitoplankton dengan frekuensi pemberian 2-3 kali sehari. Selanjutnya Notowinarto dan Putro (1992) serta James et al. (1988), juga melaporkan bahwa jenis pakan alami (fitoplankton) yang dapat diberikan pada larva teripang adalah: Dunaliella spp., Phaeodactylum spp., Tetraselmis spp., Chlorella spp., Chaetoceros spp., Nannochloropsis spp. dan Isochrysis spp. dengan frekuensi pemberian 3.4 kali sehari.

Berdasarkan pengamatan selama penelitian, pada frekuensi pemberian pakan satu dan dua kali per hari, pada saat dilakukan penyifonan banyak ditemukan plankton mati yang mengendap di dasar bak. Waktu pencucian larva yang terikut saat penyifonan, plankton yang mati juga menempel dan menyelimuti tubuh larva yang bila dibiarkan akan mengganggu gerak larva dan akhirnya menyebabkan kematian. Wardoyo (1975), melaporkan bahwa kematian plankton (fitoplankton) menyebabkan terjadinya pembusukan sehingga menimbulkan masalah bagi kualitas air terutama karena meningkatkan kandungan amonia yang merupakan racun bagi organisme air.

Frekuensi pemberian pakan tiga kali per hari ternyata memperlihatkan pertumbuhan larva yang terbaik dibandingkan dengan perlakuan lainnya. Hal ini dapat diduga bahwa larva yang diberi pakan tiga kali per hari cukup mendukung untuk proses metabolisme dan pertumbuhan. Menurut Brett (1979), beberapa faktor yang berhubungan dengan frekuensi dan jumlah pem. berian pakan setiap harinya adalah kebutuhan pakan setiap individu yang berhubungan dengan kapasitas lambung, lamanya makanan di dalam lambung (waktu kenyang) dan interval pemberi. an pakan. Selanjutnya Kono dan Nose (1971) juga mengemukakan bahwa kapasitas lambung menentukan banyak dan sedikitnya jumlah pakan yang dikonsumsi, semakin kecil volume lambung semakin sedikit yang dimakan, maka frekuensi pemberian pakan harus semakin sering.

Dari penelitian diketahui bahwa frekuensi pemberian pakan secara statistik tidak berpengaruh pada sintasan (Table 2). Rata-rata sintasan tertinggi didapat pada perlakuan $C$, kemudian diikuti perlakuan $\mathrm{D}, \mathrm{B}$ dan $\mathrm{A}$ (Figure 1). Tingkat sintasan yang tinggi merupakan faktor penting untuk produksi massal, oleh karena itu untuk produksi massal larva teripang dianjurkan pemberian pakan dengan frekuensi pakan tiga kali per hari. Hal ini sesuai dengan pendapat Jangkaru (1974) dalam Gusrina et al. (1990), bahwa interval memberi pakan yang tepat akan mempertinggi derajat efisiensi makanan sehingga menghasilkan nilai sintasan yang tinggi pula.

Table 1. Average percentage growth of sea cucumber larva stage with different feeding frequencies at 12 , 15,18 and 21 days of rearing.

\begin{tabular}{|c|c|c|c|c|c|c|c|c|c|c|c|c|}
\hline \multirow[b]{2}{*}{ Treatment } & \multicolumn{3}{|c|}{ Day 12} & \multicolumn{3}{|c|}{ Day 15} & \multicolumn{3}{|c|}{ Day 18} & \multicolumn{3}{|c|}{ Day 21} \\
\hline & & $\begin{array}{l}d^{2} \\
(\%)\end{array}$ & $p^{9}$ & $a^{9}$ & $\begin{array}{l}d^{2} \\
(\%)\end{array}$ & $p^{9}$ & $a^{9}$ & $\begin{array}{l}d^{\prime} \\
(\%)\end{array}$ & $p^{9}$ & $a^{7}$ & $\begin{array}{l}d^{*} \\
(\%)\end{array}$ & $p^{4}$ \\
\hline $\mathbf{A}$ & 86.1 & 13.9 & $\cdot$ & 79.2 & 20.8 & - & 52.9 & 47.1 & - & 28.0 & 57.0 & $15.0^{\circ}$ \\
\hline B & 69.9 & 30.1 & - & 61.1 & 38.9 & $\cdot$ & 35.2 & 63.2 & 1.6 & 27.1 & 55.5 & $17.4^{\circ}$ \\
\hline C & 63.3 & 36.7 & - & 44.8 & 55.2 & - & 30.0 & 69.0 & 1.0 & 6.5 & 42.5 & $51.0^{b}$ \\
\hline D & 67.1 & 32.9 & . & 45.5 & 54.5 & - & 27.2 & 71.0 & 1.8 & 12.8 & 53.9 & $33.8^{\text {ab }}$ \\
\hline
\end{tabular}

Abbrevation: $a^{* \prime}=$ Auricularia; $d^{*}=$ Doliolaria; $p^{\prime \prime}=$ Pentactula

Note: values in columns followed by same letters are not significantly different $(P>0.05)$ 
Pemantauan terhadap beberapa peubah kuali-. larva sesuai dengan pendapat Suwarni (1987) dan tas air yang meliputi suhu, $\mathrm{pH}$, salinitas, DO, nitrit dan amonia selama penelitian tidak menunjukkan nilai yang terlalu berfluktuasi (Table 3). Kisaran nilai yang diperoleh dianggap masih layak bagi pertumbuhan dan sintasan Sipahutar et al. (1989), bahwa teripang pasir dapat hidup pada perairan dengan suhu air 29 . $32^{\circ} \mathrm{C}$, salinitas $24-33 \mathrm{ppt}$, pH 6,5-8,5 dan oksigen terlarut 7,0-9,8 ppm.

Table 2. Survival rates of sea cucumber larvae at different feeding frequencies during 21 days of rearing.

\begin{tabular}{cc}
\hline Feeding frequencies (time/day) & $\begin{array}{c}\text { Survival rate } \\
\text { (\%) }\end{array}$ \\
\hline 1 & $28,8^{a}$ \\
2 & $33,0^{a}$ \\
3 & $42,8^{a}$ \\
4 & $38.5^{a}$ \\
\hline
\end{tabular}

Note: values in column followed by similar letter are not significantly different $(P>0.05)$

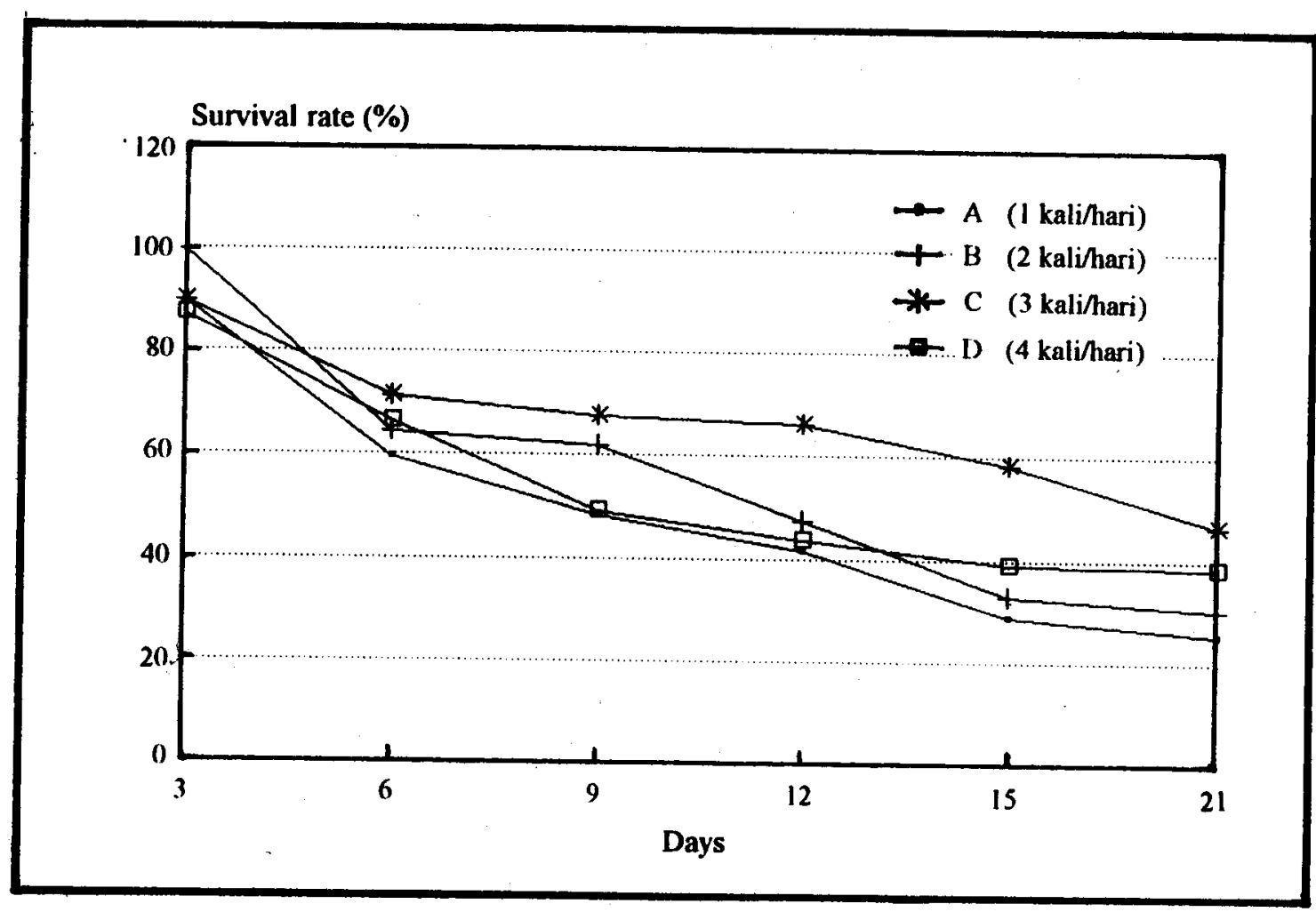

Figure 1. Survival rate of sea cucumber H. scabra larvae with different feeding frequencies. 
Moria, S.B.S.; Darmansyah; Arfah, R. dan Sugama K. Table 3. Range of water quality parameters during larvae rearing of sea cucumber $\boldsymbol{H}$. scabra with
different feeding frequencies during experimnet.

\begin{tabular}{lccccc}
\hline \multirow{2}{*}{ Variables } & & \multicolumn{5}{c}{ Treatment } \\
\cline { 3 - 6 } & & $\boldsymbol{A}$ & $\boldsymbol{B}$ & $\boldsymbol{C}$ & $\boldsymbol{D}$ \\
\hline Temperature & $\left({ }^{\circ} \mathrm{C}\right)$ & $28.0-31.5$ & $28.0-32.0$ & $28.0-31.0$ & $28.0-30.5$ \\
$p H$ & & $8.53-8.60$ & $8.52-8.62$ & $8.54-8.59$ & $8.54-8.61$ \\
Salinity & $(p p t)$ & $35-37$ & $35-37$ & $35-37$ & $35-37$ \\
Dissolved Oxygen & $(p p m)$ & $5.48-6.80$ & $5.0-6.76$ & $6.16-7.44$ & $5.64-6.32$ \\
$N_{2}-N$ & $(p p m)$ & $0.015-0.095$ & $0.015-0.126$ & $0.017-0.087$ & $0.014-0.097$ \\
$N_{4}-N$ & $(p p m)$ & $0.066-0.286$ & $0.042-0.073$ & $0.040-0.061$ & $0.042-0.047$ \\
& & & & &
\end{tabular}

\section{KESIMPULAN DAN SARAN}

Dari hasil penelitian ini dapat disimpulkan bahwa frekuensi pemberian pakan mempengaruhi pertumbuhan teripang pasir namun terhadap sintasan tidak berpengaruh. Pemberian pakan tiga kali per hari memberikan kecepatan perubahan stadium yang terbaik ( $51 \%$ mencapai stadia pentactula pada hari ke 21) dibandingkan dengan pemberian pakan satu kali, dua kali dan empat kali per hari. Adapun sintasan larva ternyata tidak dipengaruhi oleh frekuensi pemberian pakan.

\section{DAFTAR PUSTAKA}

Anonymous. 1995a. Statistik Perikanan Indonesia, 1993. Direktorat Jenderal Perikanan. Departemen Pertanian. Jakarta. 149 hal.

Anonymous. 1995b. Statistik Ekspor Hasil Perikanan 1994. Direktorat Jenderal Perikanan. Departemen Pertanian. Jakarta. 419 hal.

Brett, J.R. 1979. Environmental factors and growth. In: Fish physiology Vol.VIII. Bio-energetic and growth. Academic Press, New York. 639 pp.

Effendie, M.I. 1979. Metode biologi perikanan. Yayasan Dewi Sri, Bogor. 112 hal.

Gusrina, A. Supriatna, P.T. Imanto. 1990. Frekuensi pemberian pakan terhadap kelulushidupan dan pertumbuhan larva ikan kakap putih (Lates calcarifer). Jurnal Penelitian Budidaya Pantai. Terbitan Khusus (1) : 58-60.
James, D.B., M.E. Rajapandian., B.K. Baskar and C.P. Gapinathan. 1988. Succesful induced spawning and rearing of the Holothuria scabra J. at Tuticorin. Tut. Research Cent. of CMFRI, Tuticorin in Marine Fisheries Infomation. 87:30-33.

Jangkaru, Z. 1974. Makanan ikan. Direktorat Jenderal Perikanan. Jakarta. 51 hal.

Kono, H. and Nose. 1971. Relationship between the amount of taken and growth in fish. Frequency of feeding for maximum daily ration. Bull. Jap. Soc. Sci. Fish. 3;169.

Makatutu, D., Yunus dan I. Rusdi. 1993. Penggunaan beberapa jenis pakan alami terhadap pertumbuhan dan sintasan larva teripang pasir Holothuria scabra. J. Penel. Budidaya Pantai 9(3):97-102.

Murdjani M. dan Notowinarto. 1991. Ketimun laut, komoditas perikanan terpendam. Bull. Budidaya Laut, 1:28-29.

Notowinarto dan D.H. Putro. 1991. Teknik pembenihan teripang. Buletin Budidaya Laut No. 1. Balai Budidaya Laut Lampung. Direktorat Jenderal Perikanan. Departemen Pertanian. Jakarta. hal 33-36.

Notowinarto dan D.H. Putro. 1992. Pengamatan pendahuluan perkembangan larva teripang putih Holothuria scabra. Bull. Budidaya Laut, 5:15-25.

Notowinarto dan Suciantoro. 1992. Budidaya teripang pasir (Holothuria scabra). Seminar sehari upaya penanggulangan penyakit dalam usaha pembenihan dan budidaya udang serta peluang bisnis budidaya kepiting, teripang dan kerapu. Jakarta. 9 Juli. Balai Budidaya Air Payau, Jepara.21 hal. 
Sipahutar, D., Kusdiarti dan Harmoko. 1989. Pengamatan pendahuluan teripang pasir Holothuria scabra di perairan Bintan Selatan, Kepulauan Riau. Jurnal Penelitian Budidaya Pantai 5(1):13-18.

Sudradjat, A. dan R. Daud. 1992. Budidaya teripang dengan metode kurung tancap (hampang). Warta Penelitian dan Pengembangan Pertanian 14(2):1-3.
Suwarni. 1987. Aspek-aspek biologi beberapa jenis teripang ekonomis penting di Pulau Barang Lompo dan sekitarnya Kotamadya Ujung Pandang. Tesis. Jurusan Perikanan, Fakultas Peternakan, Universitas Hasanuddin, Ujung Pandang.

Wardoyo, T.H. 1975. Kualitas air. Institut Pertanian Bogor. Bogor. 41 hal. 